IZA DP No. 7020

Immigrants, Ethnic Identities and the Nation-State

Amelie F. Constant

Klaus F. Zimmermann

November 2012 


\title{
Immigrants, Ethnic Identities and the Nation-State
}

\author{
Amelie F. Constant \\ George Washington University, \\ Temple University and IZA \\ Klaus F. Zimmermann \\ IZA and Bonn University
}

Discussion Paper No. 7020

November 2012

\author{
IZA \\ P.O. Box 7240 \\ 53072 Bonn \\ Germany \\ Phone: +49-228-3894-0 \\ Fax: +49-228-3894-180 \\ E-mail: iza@iza.org
}

Any opinions expressed here are those of the author(s) and not those of IZA. Research published in this series may include views on policy, but the institute itself takes no institutional policy positions. The IZA research network is committed to the IZA Guiding Principles of Research Integrity.

The Institute for the Study of Labor (IZA) in Bonn is a local and virtual international research center and a place of communication between science, politics and business. IZA is an independent nonprofit organization supported by Deutsche Post Foundation. The center is associated with the University of Bonn and offers a stimulating research environment through its international network, workshops and conferences, data service, project support, research visits and doctoral program. IZA engages in (i) original and internationally competitive research in all fields of labor economics, (ii) development of policy concepts, and (iii) dissemination of research results and concepts to the interested public.

IZA Discussion Papers often represent preliminary work and are circulated to encourage discussion. Citation of such a paper should account for its provisional character. A revised version may be available directly from the author. 
IZA Discussion Paper No. 7020

November 2012

\section{ABSTRACT \\ Immigrants, Ethnic Identities and the Nation-State}

In the Western world, multiculturalism has become the way to view and form "nationhood," igniting the interest to understand and model identity. The complexity of identity formation, however, has been firm and ethnic and national identities have been deviating more and more. In this paper, we seek to investigate the nature, role and relationships between ethnic and national identities by using migrants as the natural innovators. The arrival of immigrants can amplify social challenges and both natives and immigrants can see their identities altering and evolving. Individuals in a country can be patriotic, nationalistic, indifferent, apathetic, or subvert and undermining. The openness of the people in the host country, their embracing of new cultures and their respect towards newcomers can play a major role in how immigrants react and how close they remain with the country of origin. The laws of the host country together with the ideals, the self-understanding and the foundation of the sovereign nation can also affect the identities of immigrants and natives at the individual level and at the nation-building level. We present empirical results concerning ethnic and national identities and we discuss the ramifications of the divergence between them. We review surveys and experimental contributions to the study of identity formation and its consequences for economic behavior. Before we conclude we debate the endogeneity issue of identity.

JEL Classification: F22, F52, F54, F59, J15, J16, Z10

Keywords: international migration, economic nationalism, colonialism, economics of minorities, ethnic identity, national identity, cultural economics

Corresponding author:

Klaus F. Zimmermann

IZA

P.O. Box 7240

D-53072 Bonn

Germany

E-mail: zimmermann@iza.org

\footnotetext{
* We thank an anonymous referee for many helpful comments on earlier drafts. This paper will be published as a chapter in the forthcoming handbook of Constant and Zimmermann (2013).
} 


\section{Introduction}

The concept of identity and its importance for many aspects of life as well as in the political, social and psychological realm have been studied by fellow social scientists for a long time. Sociologists, social psychologists, political scientists, anthropologists and human geographers have developed theories about the identity of individuals and created surveys to test them empirically. Indeed, they have found that identity is a significant characteristic and a distinguishing attribute that affects many facets and phases of the individual's, the group's and the society's sphere. Following the neoclassical economic theory, economists have been reluctant to delve into "exotic" questions such as how does the identity of an individual affect his or her utility function, his or her demand and supply of goods and services, or his or her demand and supply of labor; tackling the fundamental economic question of how limited resources are distributed among the different ethnicities or minorities in the host country is another question that has not been looked at. ${ }^{1}$

With the exception of Amartya Sen, Gary Becker and a few others, economists started seriously looking into the identity “variable” only in the 1990s. The notable work summarized in Akerlof and Kranton (2010) gave economists a unifying analytical framework to study the new economic man and woman who are more real than the neoclassical agent. By inserting identity in the utility function, Akerlof and Kranton (2000, 2005) opened the possibilities for the individual agent who not only derives utility from consumption and reveals her tastes but who can also draw boundaries between herself and "others" as well. For example, norms, conformity, exclusion and social distance are now possible to influence one’s labor force participation, wages, and well-being. As the authors proclaim "identity widens the scope of choices that 
economists should study” (p. 15) and provides “a new window of inequality.” The identity of an individual affects the way she reasons and makes decisions.

However, the strong rise in interest to understand and model identity in economics, has been met with a firm increase in the complexity of identity formation. In fact, individuals may have or can cultivate many identities. For instance, with the fall of the iron curtain in 1989 and with migration becoming a pressing issue anew in so many countries the economics field witnessed renewed interest in migrants, their economic performance and assimilation in the host country. Countries like Greece, Italy and Cyprus have become more heterogeneous in this process.

The importance of ethnicity has become more visible also in other parts of the world. By the end of the 20th century it was hard to find "homogeneous" countries in terms of culture, religion, ethnicity, and race. Multiculturalism became the way to view and form "nationhood" in the Western world, as it was manifested in the U.S., Canada, New Zealand, and Britain. ${ }^{2}$

In the early 2000s with "9/11” (2001) in the U.S. and the bombings in London (July 7, 2005) and Madrid (March 11, 2004) economists started paying attention to less observable but more salient characteristics of the immigrants' "being” such as ethnic identity and national identity. An individual's identification with a certain group, ethnicity, or religion can be paramount in how this individual behaves in the host country and especially towards this country’s labor market. One can have multiple identities such as one can be a mother, a nurse, a soccer fan, a punk, an immigrant, and a naturalized citizen. These identities can be compatible and reinforcing, but they can also be conflicting. Moreover, one can identify with different ethnicities and be a cosmopolitan. However, this does not necessarily mean that one does not have a 
national identity or one does not pledge allegiance to the host country. In the wide gamut of ethnic and national identities, it is possible that individuals can be patriotic, nationalistic, indifferent, apathetic, or subvert and undermining the host country.

Identity formation and preservation is, however, a two-way street. Perceptions and attitudes are central to the identity process. Permanent immigrants are particularly challenged; they face the pressure to replace the national identity of the country of origin by that of the country of immigration. Their ethnic identities may be preserved or adapted to the native ethnic identities of the host countries. The openness of the people in the new country, their embracing of new culture and their respect towards the newcomers can play a major role in how immigrants react and how close they remain with the country of origin. The arrival of immigrants in a country is bound to bring about social changes. As identities are malleable and evolve through time and space, it is very possible that the identities of the natives or autochthones will alter and normalize after they come in contact with immigrants. Finally, the laws of the host country together with the ideals, the self-understanding and the foundation of the sovereign nation can also affect the identities of immigrants and natives at the individual level and at the nation-building level.

All this can apply not only to the first generation immigrants, but it can as well transcend to the second and even third generations. The intensity and strength of allegiance to the "old country" can vary from being purely symbolic to being substantial as for example, when an active diaspora mobilizes support of the ancestor country. ${ }^{3}$

In this new era of economics in which identity directly affects the utility function of economic agents and where individuals can reach a suboptimal economic equilibrium the role of ethnic and national identity can perhaps explicate these results especially in 
the context of immigrant nations. Understanding and measuring migrant and native ethnic identities and their relationships to national identities then becomes an important task.

In this paper, we seek to investigate the nature, role of and relationships between ethnic and national identities by using migrants as the natural innovators. In the next section we first review ethnic and national identities in four different countries that together provide excellent real life paradigms of identity perceptions, formations, and issues in host countries. Modeling the ethnic identity of individuals, providing definitions and reviewing the models of identity formation solidifies this section. Discussing the ramifications of the divergence between ethnic and national identities as well as the possibilities of reconciliation concludes this section. Section 3 then presents empirical results concerning ethnic and national identities. We discuss the available data and methodology reviewing surveys and experimental contributions, study identity formation and its consequences for economic behavior. We wrap up this section with the debate of the endogeneity issue of identity. Section 4 concludes.

\section{A Conceptual Basis of Ethnic and National Identity}

\subsection{Contrasting Four Immigration Countries}

Upon entry into the new country, immigrants carry a mixture of ethnic and national identities from their home country and are facing an assimilation challenge concerning the local ethnic and national identities. Each country typically has a majority ethnic identity and a general national identity; however, there also exist sub-national identities like Bavarians and Prussians in Germany or the Scottish or Welsh in Great Britain. For simplicity, we ignore sub-national identities here. Therefore, the way how a migrant 
adjusts and perceives himself depends very much on his background from the home country and on the concrete cultural structure in the receiving country. More concretely, a Turkish migrant to Germany or the Great Btitain will face different challenges depending on whether he is from Anatolia or Istanbul and on the identity culture in the receiving country.

France, Germany, Great Britain and the United States of America can serve as paradigms of sovereign nations that are also immigrant countries. Each country/nation has applied and pursued different treatments in what political scientists call “negotiations of identities” (Kastoryano, 2002). In short, we justify the selection of the four nations through the taxonomy used in Table 1. Migrants who enter one of these countries are facing a specific culture combining the strength of the national identity with its closeness to the native ethnic identity. We argue that these four country examples are all in a separate class of national identity cultures. The United States of America and France are both strong nation states. However, while France attempts to keep the native ethnic French close to the national identity, the United States of America is a collection of many very different ethnicities. The Great Britain and Germany have a weak or loose national identity as both countries come from regions that have been independent across centuries. In addition Germany’s national identity still suffers from its Nazi history. The German ethnic identity, however, is much closer to the national identity than it is in Great Britain, where the history of the island as well as the colonial past has created a large discrepancy between the ethnic identity of the citizens (consider an Indian who is part of the British empire) and the British national identity. 
Table 1: Types of National Identity and Native Ethnic Identity

National Identity $\quad$ Native Ethnic Identity $=$ National Identity

$\underline{0=\text { No }} \quad \underline{1=\text { Yes }}$

Weak/loose

The UK

Germany

Strong/narrow

The US

France

This section aims to provide some insights in the struggle of the nations to preserve their profound ideals and maintain their sovereignty and national integrity without forcible assimilation and with respect to other peoples cultures. At the same time, the presence of immigrants in the host country can cause reactionary changes in policies, which can feed back in the identity of immigrants and generate a new round of changes. In political science lingo this is called "negotiating identities.” How the state or government negotiates identities with its people has a considerable bearing on the immigrants' ethnic and national identities with serious feedback loops and with indeterminate economic behavior.

Much like open economies benefit from international trade by trading different goods, exporting the goods in which they have a comparative advantage and importing goods they need at a lower price, countries can benefit from migration. The benefits for the host country are the highest when people with different skills than the natives move to the host country. It is differences in skills, abilities, talents and experience that make immigrants valuable to the host country. Below, we contrast the ideals and laws among these four countries and the labor market performance of their immigrants as well as the immigrants’ ethnic identities. 
France and Germany in continental Europe represent two almost diametrically opposing nation-building models. In France, it is the political unity and the tripartite Republican ideals of "liberté, égalité, fraternité” that have shaped the nation and defined citizenship. ${ }^{4}$ The "law of soil" but also the "law of blood" have determined citizenship. Ethnic identity was always viewed as an obstacle to national solidarity and to immigrant integration. Therefore, France’s immigration policy has always been to integrate foreigners into the nation by putting into practice the Enlightenment and the Republican assimilation model that aspires to efface ethnic and national origins in the second generation, so that immigrant children can hardly be distinguished from French children. This model was strengthened by the relatively relaxed citizenship laws and the integrating institutions such as schools, the military, unions, the French communist party, and the Catholic Church. It aimed at inculcating both French and immigrant children a common civic culture and the pride of French values. (Hutchinson and Smith, 1996). This is manifested by the recent decision of the French supreme court to prohibit any ostensible ethnic or religious manifestations in public and in schools such as wearing the chador or the Christian Cross.

Most immigrants in France come from France’s ex-colonies, speak the same language, have citizenship, can vote and, thus, can make a difference in choosing their representation. After the Second War, other immigrants arrived in France under guestworker schemes. While according to official statistics, the population in France is either French by birth (and origin is omitted), French by naturalization (and origin is omitted), or foreign, immigrants in France, remain not integrated in the French society; they occupy a "different” social class and maintain a clear social distance from the white native French. Their labor market attachment is poor and their economic situation 
is far worse than that of native French (Constant, 2005). Over the last decade, France is consciously trying to avoid social exclusion, and introduced the terms immigrant integration and insertion.

In Germany, in contrast, the nation was built as a natural community, homogeneous in language and culture where "Einigkeit und Recht und Freiheit” were the defining ideals. The "Volk" preceded the geopolitical formation of the state and citizenship ideas were formed later (Brubaker, 1992). This explains the emphasis of the country in the origins and bloodlines of its people. Often times, individuals unfamiliar with the German culture, language and ideals who could prove German ancestry have been granted German citizenship and access to all benefits as the natives. They are the ethnic Germans, and their enumeration as immigrants is effaced from official statistics. In summary, the idea of a German nation came late into the existence of the people as one culture; it has also suffered from the Nazi era.

Mass migration to Germany started after the Second War and was, after the waradjustment period of the 1950 s, mostly demand driven. ${ }^{5}$ While initially low skilled laborers were recruited in the 1960s, within a decade after the recruitment stop in 1973, spouses and children were the majority of immigrants. In the following years immigrants were mostly refugees due to the geopolitical changes. In the late 1990s and in the new century, Germany has reevaluated its definition, liberalized its naturalization rules, established the "law of soil," acknowledged politically the status of an immigrant country, and is actively seeking to integrate its immigrants. While Germany is opposing the universalist and assimilationist French model, it grapples with the accusation of having created "parallel societies.” 
Immigrants in Germany do not fare well in the labor market (Bauer et al., 2005). With the exception of some immigrant groups in self-employment, compared to native Germans, immigrants in general have higher unemployment rates, lower labor force participation rates, and lower earnings. These outcomes are partly explained by the individual characteristics of immigrants, which are different from those of the natives and largely related to selection. Immigrants in Germany do not often have German citizenship and, thus, they do not have political representation.

While the French and German models are completely different in their inception of the nation-state, the situation of their immigrants is similar. Ethnic enclaves and banlieus (suburban ghettos) exist in both countries, indicating sites of poverty and foreignness (Kastoryano, 2002). On top of that, the national consciousness or identity of their immigrants is also similar and it does not always align with the host country.

Great Britain is a nation that has allowed people from its ex-colonies to immigrate and be British; it practices a yet different political and civic philosophy. Citizenship and the right to vote is not only open to the British but also to those from the Commonwealth. Immigrants from Jamaica, Trinidad, Nigeria, Ghana, Uganda, Kenya, India, Pakistan and Bangladesh, for example, when they arrive in Britain have the right to vote. They can choose representatives who are more likely to be sympathetic to them and their situation (Sen, 2001). After the Second War, immigrants started flooding the country, which received them with an open mind, under the ideals of cultural diversity, and with antidiscrimination laws safeguarding their religious practices. Riots and clashes between immigrants and the police in the 1980s made the nation reconsider its nonchalant multicultural stance and enforce the learning of the English language, culture, history and values if immigrants want to stay in the country. 
These upheavals also prompted the British politician Tebbitt to propose "the cricket test” for the immigrants’ national identity and allegiance. ${ }^{6}$ While immigrants’ labor market performance in Great Britain varies by ethnic origin, some immigrant ethnicities fare very well.

The underlying motif in ethnic clashes in all these countries is that the immigrant minority ethnic groups almost unite in identification to stand against the larger dominant society with which they share the same territorial space but not the same resources. However, it also observed that immigrant groups do not share the same identity and often oppose other immigrant groups. This is another manifestation of multiple identities.

The United States of America (U.S), a prototypical immigrant nation, was created in a yet different historical context. It is heralded by the "e pluribus unum" etched on its Great Seal. It means that "many are uniting into one,” as it is the cultural diversity of the immigrants that makes up the nation and molds into one national identity: “we the people.” The U.S. as a nation emphasized commitment to three principles: liberty, equality, and self-government. ${ }^{7}$ It was identification with these principles that created the nationality of its people. In the newly created nation in the $18^{\text {th }}$ century any person could become American so long as he or she was willing to commit to the political ideology centered on these abstract ideals (Gleason, 1980). The “melting pot” symbolizes the blending of cultures, languages, religions, ideals, beliefs and ideologies. It does not mean that one culture or ethnicity is assimilated by another nor that the blending always produces the same peoplehood. What comes out of this blending is a new peoplehood with an underlying common national identity. It is 
important to note that this blending symbolizes the ever evolving American peoplehood as new "blood" comes in the country and blends with the rest.

In the early 1900s “Americanization” was encouraged and only immigrants from Germany, Scandinavia and the British Isles were allowed to enter; they were expected to resemble the Anglo-Protestant model. In 1965 the U.S. Immigration Law abolished discriminationary quota and opened up to immigrants from other hemispheres. By the end of the 20th century, one finds more and more of hyphenated Americans such as Greek-Americans, African-Americans, or Italian-Americans, etc. Hence, the myth of the melting pot today does not refer to assimilation between the ethnicities. To the contrary, the United States of America are a collection of ethnic communities with a strong and rising Spanish speaking sub-population.

Membership in the civic and national consciousness does not require a single religious, or cultural identity, but support of the democratic political values. The national security challenge with “9/11” precipitated border controls, renewed xenophobia and anti-migration discourse, victimizing some minority groups. The question of competing identities and how they threaten the nation was not just academic but real.

This section shows that the institutional and structural dimensions of national identities can shape the performance of immigrants and interfere with their ethnic identities. This suggests that one needs to take care of the potentials and challenges of multi-ethnic dimensions for the dynamics of identity formation. The host country or state has power over its citizens or legal population that cannot be ignored. This power can in turn form perceptions and attitudes - to both natives and immigrants - that are vital to the ethnic identity process and to the economic performance of immigrants. 


\subsection{Modeling Identity Formation}

Identities emerge from social interactions and become most relevant when social, cultural, and linguistic clashes are present. In the context of immigrant nations, immigrants are most likely to reconsider and alter their ethnic identities after they arrive in the host country. Multi-ethnic dimensions may appear as discussed by Constant et al. (2009) and national identities are likely to adjust as well. As discussed in section 2.1, the ethnic and national identity culture should matter much for resulting adjustments. However, the available theoretical literature has made only limited suggestions in how to deal with this complex challenge.

Hence, our knowledge is incomplete and we can only present some core approaches to the economics of identity formation which have instituted different forms of applications. Based on a very similar framework, some economists present identity as a model of conformity (Bernheim, 1994). Bernheim incorporated social factors such as status directly in the individual preferences of agents. His model can explain widely obeyed and persistent norms as well as transitory norms such as fads. Others present identity as a model of social distance and social decisions (Akerlof, 1997), as a model of economics and identity (Akerlof and Kranton, 2000), and others as a model of social identity and behavior (Benjamin et al., 2010; Georgiadis and Manning, 2013).

At the beginning of the economic literature on identity formation are also studies on racial identity norms. Darity et al. (2006) in a central paper use evolutionary game theory to study the origin and persistence of racial identity norms. In particular they study the relationship between wealth accumulation and racial identity. They argue that the formation of identity norms imposes externalities (both positive and negative) on an individual's identity actions. The authors consider three types of agents: a racialist, an 
individualist and a mixed-identity one. Both intra- and inter-group interaction are responsible for the construction of a racial identity. One equilibrium of their model is achieved when all persons follow an individualist identity strategy in which race is not important for market or non-market interactions. The other equilibrium is the racialist social norm where race is very important for both market and non-market interactions. The equilibrium of the mixed-identity strategy has both the individualist and the racialist strategy persistent in social interactions. The latter is more likely to exist under a laissez-faire organization of social interactions. Their model provides a framework for understanding acculturation and other social phenomena.

Drawing on Steward (1997), Darity et al. (2006) discuss also the use of Becker’s household production framework for modeling the demand racial-cultural identity, an approach that can be easily generalized for ethnic and national identities. Such identities are just treated as commodities that are included in the utility function of the individual in the usual fashion. ${ }^{8}$ Commodities are produced through the use of marked goods and household production time. The production technology is affected by the size of the ethnic network and the cultural conditions towards national and native ethnic identities. The private production of identity by members of some other group and the negative externalities associated with that production can lead to a negative impact on identity production of other groups. Most important, "the identity formation of individuals is affected by the prevailing norms of one’s own- and other-group racial-cultural identity” (Darity et al., 2006). Others have an effect on production and, hence, commodities and utility.

Akerlof and Kranton (2000), place the identity variable directly into the utility function of the individual, which then depends on the individual's actions, its assigned 
social categories, and the actions of others. They concentrate on general identity formation and call decreases or increases in utility that come from variations of the individual identity losses or gains in identity. Others including Benjamin et al. (2010) and Georgiadis and Manning (2013) model the choice between identity formation and normal actions using quadratic loss functions with different degrees of complexity to derive informed conclusions about the identity choices.

To expose the basic ideas, no differences are made between the many types of identities an individual may have. We also choose a simple framework related to the models used in particular by Benjamin et al. (2010) and Georgiadis and Manning (2013).

Let $x_{i}$ be some action choice by individual $i$ such as the choice to assimilate in the host country. Let $\tilde{x}_{i}$ be the individual's preferred action or her ideal action. Then, any deviation from the ideal action will be a loss to the individual, $\left(x_{i}-\tilde{x}_{i}\right)$. The individual can also belong to a social club such as be a member of her ethnic group, $C$. This belonging relates to her ethnic identity. The group may require from its members to exert action $x_{c}$. Any deviation from the ethnic "directive" will be a loss to the individual or it could be thought as the penalty she will have to pay to be a member of this ethnic group, $\left(x_{i}-x_{c}^{*}\right)$. We express this loss in a quadratic form and a weight or a parameter to it. The utility function of the individual then is: ${ }^{9}$

$$
U_{i}\left(x_{i}, c\right)=-(1-w(s))\left(x_{i}-\tilde{x}_{i}\right)^{2}-w(s)\left(x_{i}-x_{c}^{*}\right)^{2}
$$

The first term in this function is the utility from choosing to act and the second term is utility from choosing to be a member of a group. Note that $w$ is the weight with strength $s$ and $0 \leq w \leq 1$ 
To find the optimal action $x_{i}^{*}$ that will maximize her utility, we take the first order conditions and set them to zero. Then:

$$
x_{i}^{*}=\tilde{x}_{i}(1-w(s))+w(s) x_{c}^{*}
$$

This is a weighted average of the preferred action without identity considerations and with identity constraints. By inserting $x_{i}^{*}$ into the utility function, the maximized utility becomes:

$$
U_{i}\left(x_{i}, c\right)=-w(s)(1-w(s))\left(\tilde{x}_{i}-x_{c}^{*}\right)^{2}
$$

Behavioral responses can be modeled by varying $s, \tilde{x}_{i}$ or $x_{c}^{*}$. Simple calculations show that total utility is the sum of utility from acting and utility from being a member in the social club $U_{i}\left(x_{i}, c\right)=U x_{i}+U c$, and relative utility is

$$
\frac{\left(U c-U x_{i}\right)}{\left(U c+U x_{i}\right)}=1-2 w
$$

which implies

(i) $\quad U c=U x_{i}$ for $w=0.5$

(ii) $\quad U C>U x_{i}$ for $w<0.5$ and

(iii) $\quad U C<U x_{i}$ for $w>0.5$.

\subsection{Balancing Ethnic and National Identity}

In homogeneous countries ethnic and national identities are fully overlapping one another. Ethnic identities are important because they can give meaning to the individuals’ existence. They provide a purpose in life and a strong link with ancestors and descendants. National identity presumes a devotion to a country. ${ }^{10}$ However, in reality there is bifurcation between national and ethnic identities. The notions of 
citizenship, nationality, and dual nationality offer additional complexity to the issue. ${ }^{11}$ The immigrants of our times do not have a singular identity; they often oscillate between the old and the new world. ${ }^{12}$ The question that arises is how a nation can preserve its integrity and sovereignty while allowing its citizens to freely choose their ethnic identity and be happy and productive members of the new society.

In modern societies, it is efficiency and success that is sought after and not conformity or filial piety. Remarkably, as Park (1950) reflects, even though natives as a whole may appear conspicuously uniform - at least to the eyes of the immigrants - they are also individuals and can have very different opinions and beliefs from each other. Yet they all unite when it comes to their national identity, allegiance and creed. The idea of "nation building," that is, applying policies that encourage and reinforce a national identity, has been advanced as a means for peaceful integration and conflict reduction in countries with high levels of ethnic diversity or fractionalization.

The U.S. is the country that is the closest in achieving this reconciliation. While Americans are from all corners of the world with different cultures, maternal tongues, and ethnic self-identification they all say "I am an American first" and pledge allegiance to the United States of America. The following section provides examples and findings about the balancing of ethnic and national identities for the United States of America and other countries.

\section{Empirical Findings}

\subsection{Methodology and Data}

The U.S. has come a long way in balancing ethnic, racial and national identities. This is best reflected by the ethno-racial classification in the decennial censuses over the years (Lee, 2009). In 1860, for example, there was only an entry for race that had three 
options: White, Black, and Mulato. In 2000, the options for race were: White, Black, African American, or Negro, American Indian or Alaska Native, Chinese, Japanese, Filipino, Korean, Asian Indian, Vietnamese, Native Hawaiian, Guamanian or Chamorro, some other Pacific Islander, some other Asian, some other Race. In addition, there was an entry for ethnicity with the following options: Mexican, MexicanAmerican, Chicano, Puerto Rican, Cuban, other Spanish/Hispanic/Latino. Lee (2009) observes that the census questions changed "from enumerator observations to selfidentification” with the 1960 census (p. 116), and that self-identification with one race was replaced with a multiracial identification with the 2000 census.

Citrin and Sears (2009) describe the policy of the U.S. to achieve unity - given its poly-ethnic population - as one that does not publicly state one particular "ethnic or religious preference as the nation's defining identity but simply to demand as a price of nationhood that everyone endorses democratic political principles and tolerates everyone else’s customs” (p. 146). Thus, although ethnic and national identities in the U.S. do not overlap they need not be competing either. In fact, in a successful "blending of identities" scenario it is possible that "strong identifications with both nation and ethnic group are not merely compatible but may even be mutually reinforcing” (Citrin and Sears, 2009, p. 152).

A critical question that all social scientists face is how to rigorously define and successfully measure ethnic and national identities. In spite the academic literature in the social sciences, this is such a difficult task that has lead many scientists egregiously advocate to abandon it (Brubaker and Cooper, 2000). Economists have ignored the issue for a long time as it involves arguments of endogeneity and sample biases. Few words can mean such different things at the same time. Identity is one of them. As Citrin and 
Sears (2009) put it, identity means "both sameness and difference, both commonality and individuality” (p. 146).

To empirically measure ethnic identity scientists have used small scale identity tailored surveys with open-ended questions, larger nationally representative data, and experiments. In a report prepared for the UK Longitudinal Studies Centre (ULSC) about Understanding Society - a major longitudinal survey in the UK with 40,000 individuals - Nandi and Platt (2009) describe the process of development of a series of new ethnic identity questions and the rational for asking these questions based - inter alia - on a thorough review of the literature and focus groups meetings.

In Europe there are a few large datasets that include questions on ethnic identity such as the German Socio-Economic Panel (GSOEP) but they ask this question only to immigrants or foreign-born. There are hardly any surveys that ask natives about their ethnic and national identity. Other datasets such as the International Social Survey Programme offer the advantage of cross-country comparisons vis-à-vis the ethnic identity. Other surveys ask respondents how proud they are to have an identity as a particular nationality and can capture ethnic and national identity and feelings of patriotism. Such a survey is the World Values Survey (WVS) that asks respondents how proud they are to have an identity as, for example, Greek.

Using experiments, on the other hand, is not an easy task; validity and reliability cannot be compromised, and the correct choice of the control group is critical. Researchers have to spend a lot of time observing and learning the right way to run experiments. Experiments can provide intuition and open new avenues of research. Combining surveys and experiments is another way to produce useful data for analysis. Behavioral and experimental economists have run several experiments in their quest to 
test identity, social identity, natural identity, preferences, religion, and other human traits such as altruism, fairness and reciprocity.

\subsection{Findings on Ethnic and National Identities ${ }^{13}$}

Citrin and Sears (2009) provide an excellent overview of studies that attempt to measure identities and examine the competing hypothesis of the ethnic and national identities of Americans. Acknowledging the important nuance between identify 'as' and identify 'with' these studies employed the following datasets: the 1992 and 2002 American National Election Studies (ANES), the 1994 and 1996 General Social Surveys (GSS), and the 1994 to 2000 series of Los Angeles County Social Surveys (LACSS). LACSS survey respondents were asked "When it comes to political and social matters, do you think of yourself mainly as just an American, mainly as a member of an ethnic group, or both?” and responses determined their classification as a "national,” “ethnic,” or "hyphenated" American category. These three surveys also included variables that were used to create a measure of the strength of patriotic feeling. From LACSS an ethnicity measure was created to quantify the strength of connectedness with specific ethnic groups as well as the importance of ethnicity to one's overall sense of identity.

To determine identity choice, the authors used the question "When you think of social and political issues, do you think of yourself mainly as a member of a particular ethnic, racial, or nationality group, or do you think of yourself as just an American?” Ninety percent of respondents stated “just American” as their association. About half (54\%) of those respondents felt American on all issues and another 28\% felt that way for most issues. Results from LACSS are similar and reinforce the conclusion that the majority of respondents see themselves as American over any particular ethnic 
association. The majority of white respondents claimed “just American,” but interestingly a large majority of Hispanic and black respondents placed nationality over ethnicity in their responses. When given a follow-up choice in the LACSS survey minority respondents would often list themselves as having dual or hyphenated identity. Differences can be seen among the minority groups, however. A larger percent of black respondents stuck with identifying as “just an American;” more Hispanics and Asians responded with ethnic identity only. Using Hispanic respondents as an example, results show that native-born Hispanics are more likely to identify as “just American” while foreign born respondents are likely to identify more with ethnicity solely. Overall there is a majority of respondents who chose to identify as “just American” across all minorities. If given the option, there is a majority of minority respondents who will identify using a hyphenated label. Those who prefer a purely ethnic identity are foreignborn immigrants.

In another survey, the Pilot National Asian American Political Survey, with 1,218 adults older than eighteen years of age respondents were asked which of the following they were identifying 'as' in general: American, Asian-American, Asian, ethnic-American, or their own national origin. The overwhelming majority (61\%) chose some form of American identity.

Citrin and Sears (2009) further created a model of identity choice with independent variables including age, income, education, race, ethnicity, and an index of immigration status. Results of their multinomial logit model show that the more experiences and claims (birth, citizenship) that one has in America, the more likely they are to identify as "just an American.” Age also increases the response as solely American identification although the authors do not have an explanation for this. Whites 
still exhibit the strongest identification as American, but as immigrants move further away from their immigration time/experience their likelihood of identifying as "just American” increases.

The same study also tested patriotism with questions about love and pride in America and the American flag using the 2002 American National Election Study. Ninety-one percent of respondents across all ethnic groups expressed an extremely or very strong love for the United States and 85\% expressed very high levels of pride in the American flag. Like identification, feelings of patriotism increase as time-sincemigration increases. Regarding the strength of ethnic attachment, the authors used the questions: “How strongly do you identify with other (ethnicity) people?”; “How important is being (ethnicity) to your sense of identity?”; and “How often do you think of yourself as an (ethnicity) person?” Interestingly, all ethnic and racial minorities identified ethnically more than whites, however, Asians had a rate only marginally higher than that of whites. As with other measures in this study, more recent immigrants exhibit a stronger ethnic attachment.

Citrin and Sears (2009) next examined if a strong ethnic identity compromises national unity. Using LACSS, they studied three ethnic groups: Whites, Blacks, and Hispanics. America has traditionally been dominated by white, European Christians so identification collisions for whites should not be a problem. For minority groups, however, ethnic and national identification may collide. There is also the possibility that no matter what background, Americans will endorse the idea of a melting pot, a unified country no matter what their individual ethnicity is. As would be expected, those identifying as "just an American" have the weakest ethnic connection. Those who identify as hyphenated are more likely to respond as solely ethnic identifying 
respondents do. Those choosing to identify as solely ethnic are the only groups that show diminished levels of patriotism. Overall, the authors find that ethnic identity “appears to compromise patriotism toward America only at the extremes” (p. 171), and that the "strength of national identity is pervasive" (p. 173).

UNESCO’s International Journal on Multicultural Societies published a series of research papers in 2005 about national identity and attitudes towards migrants, based on findings from the International Social Survey Programme (ISSP). Within this series, Heath and Tilley (2005) focused their research on British national identity and attitudes towards immigration, exploring the distinction between ethnic and civic conceptions. The authors find that Britain is not as 'open arms' to migrants who would like to immigrate. The majority of the sample (75\%) said that the number of immigrants to Britain should be reduced and four-fifths said that illegal immigrants should be expelled. On the other hand, the authors find that once immigrants are in the country the British are more forbearing. For example, respondents did not have particular views about the assimilation of immigrants or about multiculturalism; they favored, however, laws that outlaw racial discrimination. While civic aspects are very important for British identity, patriotism is not. The authors conclude with the speculation that Britain may gradually move towards a "civic only" conception of identity.

Manning and Roy (2010) study the extent and determinants of national identity in Britain using the UK Labour Force Survey. Overall, the authors find evidence for a culture club, and in fact one connected with Muslims. The vast majority of those born in Britain, of whatever ethnicity or religion, think of themselves as British. While newly arrived immigrants do not think of themselves as British, with additional years of living 
in the UK they do. Interestingly, this acculturation into the British national identity occurs sooner for immigrants from poorer and less democratic countries of origin. Georgiadis and Manning (2013) investigate the correlates of national identity in Great Britain using the 2007 Citizenship Survey of England and Wales administered by the Department for Communities and Local Government. Respondents reveal what they consider what their national identities are to identify whether they consider themselves to be British and how strong they feel they are. This is correlated with factors covering ethnicity, religion, English language proficiency, discrimination, the economic background, among others. White as non-white natives exhibit a very high British national identity, while non-white immigrants report much lower values. The main finding of the paper is that people feeling well treated and tolerated with their values and actions are more likely to identify with the country and to feel that they belong to society. People who are more surrounded by likes have a stronger feeling to belong to the country. Religious minorities are more probable to experience conflicts between religion and national identity.

Clots-Figueras and Masella (2008) study how governments can affect and alter individual identity through the education curricula. After Catalan was taught in Spanish schools in 1983 pupils and their parents were more likely to have a Catalan identity and vote for Catalans in elections even if they had no Catalan origins.

Using data from the World Values Survey, Masella (2011) finds no evidence that individuals in more ethnically diverse countries have a less intense national identity. Examining the issue separately for minorities and majorities, the author finds that the minority has stronger national sentiments than the majority when the country is less ethnically diverse, and less intense national sentiments than the majority when the 
country is more ethnically diverse. The author finally finds weaker national sentiments among larger groups and a lower connection with the ethnic group when individuals have high incomes.

\subsection{Identities in Economics and the Labor Markets}

People's identities and especially the ethnic identities of migrants are important in economics because ethnic identities define who people think they are, how they perceive themselves with respect to others and how they make decisions in their everyday life. These decisions, for example, may have to do with the purchasing preferences of individuals as consumers, with their decisions to invest in human capital, to work or to pay taxes. ${ }^{14}$ Identity economics can now explain the sub-optimal (from the point of view of the neoclassical economics) behavior of choosing a profession and accepting lower than competitive wages rates. Constant and Zimmermann (2011) provide more analysis of how the ideal self and ideal fitting of an individual in a group can lead to "not-rational” economic outcomes.

Alesina and La Ferrara (2005) offer an excellent survey of the economic costs and benefits of ethnic diversity in developed and developing countries. They also reflect on the endogenous formation of political jurisdictions and call for more research on the endogenous formation of ethnic identity and the measurement of ethnic diversity.

Bisin et al. (2011) examine the correlation between ethnic identity and labor market outcomes of non-EU immigrants in Europe using the European Social Survey. The authors find that immigrants who express a strong identity are penalized in the labor market. Notably, there is a penalty of $17 \%$ for the first generation immigrants. While second-generation immigrants have the same probability of being employed as the 
natives, they have a lower probability of finding a job when they have a strong identity. Interestingly, the authors find that labor market policies and types of integration significantly affect the relationship between ethnic identity and employment prospects. While more elastic labor markets facilitate immigrants’ employment, no market can protect immigrants from unemployment if they have strong ethnic identities.

Using the German Socioeconomic Panel, Casey and Dustmann (2010) study the self-identification of immigrants with the home and host countries, and investigate how identification with either country relates to immigrants' and their children’s labor market outcomes. The authors find that identifying with either country is only weakly related to labor market outcomes. Lastly, they find a strong intergenerational transmission of identity from one generation to the next.

Benjamin et al. (2010) in their social identity and preferences paper use experimental data to infer causal effects between identity norms and economic decisionmaking. Specifically, they tested the effect of ethnic, racial, and gender category norms on time preference and risk preference. Using methodology from social psychology and taking the self-categorization theory as given, they ran experiments of AsianAmericans, native black Americans, immigrant black Americans, white Americans, and men and women. By “priming” the laboratory subjects, they were able to find the marginal effect of increasing the strength of affiliation with that category.

The authors find that Asian-Americans are less patient and more risk averse than whites when are not primed, that is, when the social identity and norms of the group are not considered. However, when they are ethnically primed, Asian-Americans are significantly more patient with time. This result confirms the characteristic of AsianAmericans being more patient. Regarding risk preferences, priming did not change their 
responses. Further testing intertemporal choices, the authors found that for AsianAmericans to differ payment when their ethnic identity is made salient, the interest rate must decrease dramatically.

Interesting results they also were found for blacks in the U.S. Making race salient to native blacks decreases the interest rate in intertemporal choices. This is also in line with representative national data that show that black Americans are risk averse. However, race salience had no effect on the intertemporal choices of black immigrants or the whites. Regarding risk preferences, the authors found that black Americans are more risk averse when the race is salient, a result that is consistent with norms that black Americans do not participate in the stock market and are less likely to be entrepreneurs.

Pendakur and Pendakur (2005) study how ethnic identity affects labor market behavior in Canada. Using a direct measure of ethnic identity from a survey question which asks "is your ethnic origin very important to you, somewhat important, not very import or not at all important," they examine the impact of ethnic identity on the use of informal networks to find jobs and on the quality of jobs found. The authors find that ethnic identity is associated with the tendency to use informal methods to find a job. The correlation varies across ethnic groups and depends on the size of ethnic communities. White European ethnic minorities, for example, who said that ethnic origin is 'very important,' and who live in areas with large co-ethnic populations are about 25\% more likely to use informal networks to find a job compared to comparable Europeans in small co-ethnic populations areas. In addition, men with strong ethnic identity who are also phenotypical minorities, have much lower occupational prestige. 
Schandevyl (2010) looks at the Belgian trade unions in relation to immigrant members and their ethnic identity. In a country that is divided in two cultures and identities - the French speaking and the Dutch speaking - immigrants and their various cultures and ethnic identities have added a serious challenge to the national trade unions. Diversity and even conflicts of identity among the union members jeopardize the sense of unity and solidarity that characterizes labor unions. Based on transcripts of trade union conventions and meetings, and on interviews the author conducted with activists and officials within unions, she shows both the evolving thinking on identity and the development of union structures in relation to migration.

\subsection{Endogeneity and Causality}

The way the models are set up and because identity can alter and remain fluid economists are always facing the potential of endogeneity; often, the causality interpretation is dubious. Hence, one needs to admit that estimated relationships are often “just” correlations and do not reveal causal structures. This does not mean, however, that such an analysis is useless given the few meaningful settings (exogenous variation, important research issue, interpretable regressors) we have in economics. In studies of racial identities, for example the Darity et al. (2006) paper, there is an exogenous and an endogenous part of identity. Looking at blacks and mulattos in the deep South in the US in the mid-19th century, Bodenhorn and Ruebeck (2003) are able to show that mulattos could alter their racial identity to advance and enjoy labor market benefits. While adopting a mulatto identity generates pecuniary gains, it also inflicts psychic costs to individuals. In conclusion, the authors reflect that their results imply that race is contextual. 
A way to circumvent the endogeneity issue is with experiments. Benjamin et al. (2010) follow social psychology methods to introduce an exogenous variation in identity. In "self-categorization theory," “primes” or environmental cues can render temporarily - a person's behavior to lean toward the norms associated with the salient category. Accordingly, experimental scientists can identify the marginal effect of a particular social category by priming subjects. Indeed, the authors prime identities with unknown norms so that they can infer what those norms are via the behavioral response to the prime. The idea here is that priming a particular social category reveals the marginal effect of increasing the strength of affiliation with that category.

\section{Conclusion}

While there is a rising interest in economics in the determinants and consequences of ethnic and national identities among individuals, groups and nations, and the various cultural backgrounds, research in this area is just at the beginning. There are some theories and studies on ethnic identity formation and its consequences, see also Constant and Zimmermann (2011). With few notable exceptions there is only limited evidence of national identity. Even more, the joint evolution of migrant ethnicity, native ethnicity and national identities are not well understood. This is in particular true if one studies and incorporates the complex picture of national identity structures and policies across the nation states. 


\section{References}

Akerlof, G. A. (1997), 'Social Distance and Social Decisions’, Econometrica, 65, 10051027.

Akerlof, G. A. and R. E. Kranton (2000), ‘Economics and Identity’, Quarterly Journal of Economics, 115 (3), 715-753.

Akerlof, G. A. and R. E. Kranton (2005), 'Identity and the Economics of Organizations', Journal of Economic Perspectives, 19 (1), 9-32.

Akerlof, G. A. and Rachel E. Kranton (2010), Identity Economics. How our Identities Shape our Work, Wages, and Well-being, Princeton and Oxford: Princeton University Press.

Alesina, A. and E. La Ferrera (2005), 'Ethnic diversity and economic performance', Journal of Economic Literature, 43, 762-800.

Bauer, T., B. Dietz, E. Zwintz and K. F. Zimmermann (2005), ‘German Migration: Development, Assimilation, and Labour Market Effects', in Klaus F. Zimmermann, (ed), European Migration: What Do We Know? Oxford/New York: Oxford University Press, pp. 197-261.

Benjamin, D. J., J. J. Choi and A. J. Strickland (2010), ‘Social Identity and Preferences’, American Economic Review, 100, 1913-1928. 
Bernheim, B. D. (1994), ‘A Theory of Conformity’, Journal of Political Economy, 102 (5), 821-877.

Bisin, A., E. Patacchini, T. Verdier and Y. Zenou (2011), 'Ethnic Identity and Labour Market Outcomes of Immigrants in Europe', Economic Policy, 26 (65), 57-92.

Bodenhorn, H. and C. H. Ruebeck (2003), 'The Economics of Identity and the Endogeneity of Race', NBER Working Paper No. 9962, Cambridge, MA: National Bureau of Economic Research.

Brubaker, Rogers (1992), Citizenship and Nationhood in France and Germany, Cambridge MA: Harvard University Press.

Brubaker, R. and F. Cooper (2000), ‘Beyond 'Identity’, Theory and Society, 29 (1), 147.

Casey, T. and C. Dustmann (2010), ‘Immigrants’ Identity, Economic Outcomes and the Transmission of Identity across Generations’, Economic Journal, 120 (542), F31-F51.

Citrin, Jack and David O. Sears (2009), 'Balancing National and Ethnic Identities: The Psychology of E Pluribus Unum', in Rawi Abdelal, Yoshiko M. Herrera and Alastair I. Johnston (eds), Measuring identity: A guide for social scientists, Cambridge: Cambridge University Press, pp. 
Clots-Figueras, I. and P. Masella (2008), Education, Language, and Identity, Mimeo, accessed in Sep. 2012. http://www.econ.ed.ac.uk/papers/catalan.pdf.

Constant, A. (2005), 'Immigrant Adjustment in France and Impacts on the Natives' in Klaus F. Zimmermann (ed), European Migration: What Do We Know?, Oxford, UK: Oxford University Press, pp. 263-302.

Constant, A. F., L. Gataullina and K. F. Zimmermann (2009), 'Ethnosizing Immigrants', Journal of Economic Behavior and Organization, 69 (3), 274-287.

Constant, A. F. and K. F. Zimmermann (2011), 'Migration, Ethnicity and Economic Integration' in M. N. Jovanovic (ed), International Handbook of Economic Integration,. Edward Elgar Publishing: Cheltenham, UK, pp. 145-168.

Darity, W. A. Jr., P. L. Mason and J. B. Stewart (2006), 'The Economics of Identity: The Origin and Persistence of Racial Identity Norms', Journal of Economic Behavior and Organization, 60, 283-305.

Georgiadis, A. and A. Manning (2013), 'One Nation Under a Groove? Understanding National Identity', Journal of Economic Behavior \& Organization, forthcoming.

Gleason, Philip (1980), ‘American Identity and Americanization’, in Thernstrom A. Stephan, Ann Orlov and Oscar Handlin (eds), Harvard Encyclopedia of American Ethnic Groups, Cambridge, MA: The Belknap Press of Harvard University Press, pp. . 
Harttgen, K. and M. Opfinger (2012), 'In the Nation we Trust: National Identity as a Substitute for Religion’, mimeo, Hannover.

Heath, A. F. and J. R. Tilley (2005), 'British National Identity and Attitudes Towards Immigration', International Journal on Multicultural Societies, 7 (2), 119-132.

Hutchinson, John and Anthony D. Smith (eds) (1996), Ethnicity, Oxford, New York Oxford University Press.

Kastoryano, Riva (2002), Negotiating Identities: States and Immigrants in France and Germany, Princeton: Princeton University Press.

Lee, Taeku (2009), 'Between Social Theory and Social Science Practice: Toward a New Approach to the Survey Measurement of "Race”,' in Rawi Abdelal, Yoshiko M. Herrera, Alastair I. Johnston and Rose McDermott (eds), Measuring Identity. A Guide for Social Scientists, Cambridge, MA: Cambridge University Press, pp. 113-144.

Li, X. S. (2010), 'Social Identities, Ethnic Diversity, and Tax Morale’, Public Finance Review, 38 (2), 146-177.

Manning, A. and S. Roy (2010), 'Culture Clash Or Culture Club? National Identity in Britain', The Economic Journal, 120, F72-F100. 
Masella, P. (2011), 'National Identity and Ethnic Diversity', Journal of Population Economics, doi:10.1007/s00148-011-0398-0, 1-18.

Nandi, A. and L. Platt (2009), 'Developing Ethnic Identity Questions for Understanding Society, the UK Household Longitudinal Study', Understanding Society, Working Paper Series, No. 2009 - 03, Swindon: Economic and Social Research Council.

Park, R. E. (1950), Race and Culture, The Free Press.

Pendakur, K. and R. Pendakur (2005), 'Ethnic Identity and the Labour Market’, Research on Immigration and Integration in the Metropolis, Working Paper Series No. 05-10.

Putnam, R. D. (2007), 'E Pluribus Unum: Diversity and Community in the Twenty first Century’, Scandinavian Political Studies, 30, 137-174.

Schandevyl, E. (2010), Identity, Migration and Diversity in Belgian Trade Unions, National Identities, 12 (4), 351-364.

Sen, A. (2001), 'Other People’, Proceedings of the British Academy, 111.

Stewart, J. (1997), 'NEA presidential address, 1994: toward broader involvement of Black economists in discussions of race and public policy: a plea for a reconceptualization of race and power in economic theory', in J. B. Stewart (ed), 
African Americans and Post-Industrial Labor Markets, New Brunswick, N.J.:

Transactions Publishers.

Zimmermann, Klaus F. (1996), 'European Migration: Push and Pull’, Supplement to The World Bank Economic Review and The World Bank Research Observer, 10 (1995), 313-342, reprinted in International Regional Science Review, 19 (1996), 95-128; Klaus F. Zimmermann and Thomas Bauer (eds) (2002), The Economics of Migration, Cheltenham: Edward Elgar Publishing Ltd., Vol. I, Part I, pp. 70-99.

Zimmermann, K. F., A. F. Constant and L. Gataullina (2009), 'Naturalization Proclivities, Ethnicity and Integration', International Journal of Manpower, 30 (1-2), 70-82.

Zimmermann, Klaus F. and A. F. Constant (eds.), International Handbook on the Economics of Migration, Cheltenham: Edward Elgar Publishing Ltd., forthcoming 2013. 


\section{Endnotes}

${ }^{1}$ With the exception of Jews and the State of Israel, migrants are typically members of the majority in their country of origin and become members of the minority in the new country.

${ }^{2}$ Putnam (2007) has stressed the strong challenges caused by the rising social and ethnic heterogeneity in most advanced countries.

${ }^{3}$ See the chapter of Plaza on Diaspora Resources and Policies (forthcoming in 2013).

${ }^{4}$ See Constant (2005) for a deeper inspection of the French immigration policy.

${ }^{5}$ For a further analysis of the German situation see Zimmermann (1996) and Bauer et al. (2005).

${ }^{6}$ Interestingly, the cricket test does not involve racial or other observable characteristics that can have any additional discriminatory consequences.

${ }^{7}$ For instance, it is understood that the state should exert limited involvement in society and economics.

${ }^{8}$ See Stewart (1997) and Darity et al. (2006) p. 291 and footnote 3.

${ }^{9}$ This formulation follows Benjamin et al. (2010) with the weights adding up to one for simplicity, while Georgiadis and Manning (2013) use a set of independent parameters in the utility function to impose flexibility to derive more meaningful implications for their empirical investigation.

${ }^{10}$ Another strand of literature about national identity perceives it as a substitute for religion (Harttgen and Opfinger, 2012). They constructed an index of national identity and found that social heterogeneity affects national identity through religious diversity. That is, when religious diversity is high individuals cannot identify with religion; they find national identity as a substitute for common values and norms. 
Note that it is also possible that religion is a substitute for national identity. This is often the case in Arab nations.

${ }^{11}$ See for these issues the chapter of DeVoretz on Immigrant Citizenship Ascension (forthcoming 2013) and Zimmermann et al. (2009).

${ }^{12}$ See the chapter of Constant et al. on Circular Migration (forthcoming 2013) for the analysis of circularity.

${ }^{13}$ Our Migration and Ethnicity chapter (forthcoming 2013) contains more literature on the determination of ethnicity including Constant et al. (2009) which does not have to be surveyed here again.

${ }^{14} \mathrm{Li}$ (2010) using the European and World Values Surveys investigates the impact of individuals' social identities on their tax attitudes controlling for the ethnic fragmentation of the country. In the analysis, the author considers majority and minority groups. She finds that both ethnic and national identities play important roles shaping tax morale, namely, in countries with high ethnic fractionalization tax morale is poorer. 